\title{
Perinatal and maternal outcome in meconium stained amnioticfluid (thin and thick) at dhiraj general hospital, a rural tertiary health centre
}

\author{
Jitendra V. Shukla, Arpana D. Patel, Piyusha Chandrayan*
}

Department of Obstetrics and Gynaecology, SBKS MC and RC, Baroda, Gujarat, India

Received: 02 November 2021

Accepted: 25 November 2021

\author{
*Correspondence: \\ Dr. Piyusha Chandrayan, \\ E-mail: piyusha011@gmail.com
}

Copyright: () the author(s), publisher and licensee Medip Academy. This is an open-access article distributed under the terms of the Creative Commons Attribution Non-Commercial License, which permits unrestricted non-commercial use, distribution, and reproduction in any medium, provided the original work is properly cited.

\begin{abstract}
Background: To determine the perinatal outcome of with Meconium-stained amniotic fluid (MSAF) compared with clear amniotic fluid at Dhiraj Hospital.

Methods: A prospective observational study was carried out in obstetrics and gynaecology department of Dhiraj Hospital, Sumandeep Vidyapeeth from March 2021 to August 2021. All patients fulfilling inclusion and exclusion criteria as mentioned above were taken for the study. All the categorial variables were analysed independently with the help of chi square test and fisher's exact test and all the continuous variables were analysed with independent ' $t$ test'.

Results: Out of 500 patients selected for the present study which had inclusion criteria, $13.6 \%$ were meconium stained out of which 50 (73.5\%) cases had thin meconium and 18 (26.4\%) cases had thick meconium. Fetal CTG abnormalities were more common in MSAF group and were noted in $38.2 \%$ of cases which is significantly increased compared to control group with CTG abnormalities in $8.3 \%$. The difference was significant with p value of $<0.001$. $32(47.0 \%)$ patients with meconium-stained amniotic fluid had normal vaginal delivery, while in control group out of 432, $360(83.3 \%)$ delivered normally. Incidence of LSCS and assisted vaginal delivery was more in meconium-stained amniotic fluid.

Conclusions: Meconium-stained amniotic fluid is associated with more frequency of operative delivery, birth asphyxia, neonatal sepsis, and neonatal intensive care unit admissions compared to clear amniotic fluid. Better perinatal outcome in clear amniotic fluid compared to meconium stained liquor.
\end{abstract}

Keywords: Meconium stained liquor, Meconium aspiration syndrome, Birth asphyxia, Hypoxic ischemic encephalopathy

\section{INTRODUCTION}

Meconium-stained amniotic fluid (MSAF) is usually seen in 12 to $16 \%$ of deliveries. ${ }^{1}$ Meconium passage is less common before 37 weeks of gestational age and increases steadily with gestational age. ${ }^{2}$ It may represent the normal gastrointestinal maturation, or it may indicate an acute or chronic hypoxic event, thereby making it a potential warning sign of a fetal compromise. ${ }^{3,4}$ The amniotic fluid provides a protective environment and acts as a cushion for the baby. The amniotic fluid is formed from foetal urine and is also contributed by secretions from amniotic membranes and foetal skin. ${ }^{5}$ If meconium is present in amniotic fluid this is considered as a sign of fetal distress and is associated with significant perinatal complications and outcome which includes low APGAR scores, higher incidence of chorioamnionitis, increased admission to neonatal intensive care and perinatal death. The fetus mostly does not pass meconium before 34 weeks. After 37 weeks, the risk of meconium passage increases with increasing gestational age, and it is commonly seen in post term babies. It is due to maturation of fetal 
myelination and parasympathetic innervations. Aspiration of meconium can be; in utero with fetal gasping or with the first breath after birth. ${ }^{2}$

However, it is not mandatory to have low APGAR score, acidosis or clinical illness in fetuses with meconiumstained liquor. Thus, the neonatal outcome in meconium stained liquor is comparable to deliveries with clear amniotic fluid, with normal fetal heart rate. Perinatal morbidity is high in fetus with abnormal heart rate. ${ }^{6}$ Meconium-stained amniotic fluid can result in adverse outcome of fetus and thus has been considered to cause poor perinatal outcome. This observational study was carried out to find out the perinatal outcome in meconium-stained liquor compared to clearliquor.

\section{METHODS}

A prospective observational study was carried out in obstetrics and gynaecology department of Dhiraj hospital, Sumandeep vidyapeeth from March 2021 to August 2021.

\section{Inclusion criteria}

The inclusion criteria in given study were: women in labor with full term pregnancy (>37 weeks gestation), with cephalic presentation and singelton live pregnancy.

\section{Exclusion criteria}

Exclusion criteria in given study were: cephalopelvic disproportion (CPD), malpresentation, LMP not known in labour, preexisting medical illness like pre-eclampsia, GDM, and IUGR, babies and intapartum complications like eclampsia, antepartum hemorrhage.

\section{Procedure}

All patients fulfilling inclusion and exclusion criteria as mentioned above were taken for the study. After taking proper history and clinical examination, all patients were allowed to go in labour and the labour was thoroughly watched. Patients who had meconium-stained liquor on spontaneousor artificial rupture of membrane were taken as cases. Other patients who did not have meconiumstained liquor in labour were taken as controls. Time of meconium passage and consistency of meconium wasnoted in each case. The meconium cases were seperately identified as thin and thick meconium. Fetal heart rate was monitored on CTG throughout labour. Mode of delivery whether spontaneous, operative- vaginal or LSCS was noted in each case. APGAR scoring at 1 and 5 minutes, need for resuscitation, in baby was noted. NICU admission for complications like respiratory distress syndrome, aspiration pneumonia, birth asphyxia, septicemia, jaundice, convulsion, hypoxic ischemic encephalopathy was noted. Total duration of hospital stay of neonate was noted.

\section{Statistical analysis}

As this was a prospective observational study, purposive sampling was done. All the categorial variables were analysed independently with the help of chi square test and fisher's exact test and all the continuous variables were analysed with independent ' $t$ test'.

\section{RESULTS}

Total 500 patients were enrolled in the study and the data was collected and is presented in the following tables. Out of 500 patients selected for the present study which had inclusion criteria, $13.6 \%$ were meconium stained out of which $50(73.5 \%)$ cases had thin meconium and 18 (26.4\%) cases had thick meconium. Fetal CTG abnormalities were more common in MSAF group and were noted in $38.2 \%$ of cases which is significantly increased compared to control group with CTG abnormalities in $8.3 \%$. The difference was significant with $\mathrm{p}$ value of $<0.001$.

Table 1: Incidence of MSAF.

\begin{tabular}{|c|c|c|}
\hline $\begin{array}{l}\text { MSAF (cases) } \\
\text { N }(\%)\end{array}$ & $\begin{array}{l}\text { NMSAF (controls) } \\
\text { N }(\%)\end{array}$ & Total \\
\hline $68(13.6)$ & \multirow{3}{*}{$432(86.4)$} & \multirow{3}{*}{500} \\
\hline Thick & & \\
\hline $50(73.5) \quad 18(26.4)$ & & \\
\hline
\end{tabular}

Table 2: FHR abnormality in different groups.

\begin{tabular}{|lllll|}
\hline $\begin{array}{l}\text { FHR } \\
\text { abnorm- } \\
\text { ality }\end{array}$ & $\begin{array}{l}\text { Ctatus } \mathbf{N}(\boldsymbol{\%}) \\
\mathbf{( N = 6 8 )}\end{array}$ & $\begin{array}{l}\text { Control } \\
\mathbf{( N = 4 3 2 )}\end{array}$ & $\begin{array}{l}\text { Total } \\
(\mathbf{n}=500)\end{array}$ & $\begin{array}{l}\text { P } \\
\text { value }\end{array}$ \\
\hline $\begin{array}{l}\text { Present } \\
\text { N }(\boldsymbol{\%})\end{array}$ & $26(38.2)$ & $36(8.3)$ & $62(12.4)$ & 0.0001 \\
\hline
\end{tabular}

Table 3: FHR abnormality in cases.

\begin{tabular}{|lllll|}
\hline $\begin{array}{l}\text { FHIR } \\
\text { abnorm- } \\
\text { ality }\end{array}$ & $\begin{array}{l}\text { Cases }(\text { MSAF }) \\
\text { Thin }\end{array}$ & Thick & Total & $\begin{array}{l}\text { P } \\
\text { value }\end{array}$ \\
\hline $\begin{array}{l}\text { Present } \\
\text { (\%) }\end{array}$ & $10(20)$ & $16(88)$ & $26(38.2)$ & 0.532 \\
\hline $\begin{array}{l}\text { Absent } \\
\text { N }(\%)\end{array}$ & $40(88)$ & $2(11.1)$ & $42(61.8)$ & 0.0001 \\
\hline
\end{tabular}

When the subgroups of thick and thin meconium were compared, the thick meconium group showed more frequent fetal heart rate changes. Variable deceleration was the most common CTG abnormality noted. 32 $(47.0 \%)$ patients with meconium-stained amniotic fluid had normal vaginal delivery, while in control group out of 432, $360(83.3 \%)$ delivered normally. Incidence of LSCS and assisted vaginal delivery was more in meconiumstained amniotic fluid. On comparing the subgroups of thick and thin meconium, it was the thick group where 
operative intervention was more commonly needed. The difference between subgroups is insignificant with $p$ value of 0.125 . Relatively higher $p$ value is due to low number of cases in thick subgroup.

Table 4: Mode of delivery.

\begin{tabular}{|c|c|c|c|c|}
\hline \multirow{2}{*}{$\begin{array}{l}\text { Mode of } \\
\text { delivery }\end{array}$} & \multicolumn{2}{|c|}{$\begin{array}{l}\text { Cases (MSAF) } \\
\mathbf{N}(\%)\end{array}$} & \multirow[t]{2}{*}{ Total } & \multirow[t]{2}{*}{$\begin{array}{l}\mathbf{P} \\
\text { value }\end{array}$} \\
\hline & Cases & Control & & \\
\hline $\begin{array}{l}\text { Normal } \\
\text { vaginal }\end{array}$ & $\begin{array}{l}32 \\
(47)\end{array}$ & $\begin{array}{l}360 \\
(83.3)\end{array}$ & $\begin{array}{l}392 \\
(78.4)\end{array}$ & 0.0001 \\
\hline $\begin{array}{l}\text { Assisted } \\
\text { vaginal }\end{array}$ & $\begin{array}{l}6 \\
(8.8)\end{array}$ & $\begin{array}{l}43 \\
(5.3)\end{array}$ & $\begin{array}{l}29 \\
(5.8)\end{array}$ & 0.056 \\
\hline LSCS & $\begin{array}{l}30 \\
(44.1)\end{array}$ & $\begin{array}{l}29 \\
(11.3)\end{array}$ & $\begin{array}{l}79 \\
(15.8)\end{array}$ & 0.053 \\
\hline
\end{tabular}

Table 5: Mode of delivery in MSAF cases.

\begin{tabular}{|c|c|c|c|c|}
\hline \multirow{2}{*}{$\begin{array}{l}\text { Mode of } \\
\text { delivery }\end{array}$} & \multicolumn{2}{|c|}{$\begin{array}{l}\text { Cases (MSAF) } \\
\mathbf{N}(\%)\end{array}$} & \multirow[t]{2}{*}{$\begin{array}{l}\text { Total } \\
(n=68)\end{array}$} & \multirow[t]{2}{*}{$\begin{array}{l}\mathbf{P} \\
\text { value }\end{array}$} \\
\hline & $\begin{array}{l}\text { Thin } \\
(\mathrm{N}=50)\end{array}$ & $\begin{array}{l}\text { Thick } \\
(\mathrm{N}=18)\end{array}$ & & \\
\hline $\begin{array}{l}\text { Normal } \\
\text { vaginal }\end{array}$ & $\begin{array}{l}30 \\
(60)\end{array}$ & $\begin{array}{l}3 \\
(16.6)\end{array}$ & $\begin{array}{l}33 \\
(48.5)\end{array}$ & 0.0001 \\
\hline $\begin{array}{l}\text { Assisted } \\
\text { vaginal }\end{array}$ & $\begin{array}{l}3 \\
(6)\end{array}$ & $\begin{array}{l}2 \\
(11.1)\end{array}$ & $\begin{array}{l}5 \\
(7.35)\end{array}$ & 0.763 \\
\hline LSCS & $\begin{array}{l}17 \\
(34)\end{array}$ & $\begin{array}{l}13 \\
(72.2)\end{array}$ & $\begin{array}{l}30 \\
(44.1)\end{array}$ & 0.273 \\
\hline
\end{tabular}

If meconium first appeared in the latent phase, the incidence of LSCS was more as compared to when it appeared in the second stage. Overall incidence of LSCS was higher if the meconium was thick. Moreover the LSCS incidence was much higher if the meconium was thick irrespective of stage. Low Apgar score at 1 and 5 minutes was more prevalent in MSAF compared to control with $\mathrm{p}$ value of $<0.001$. At 1 minute the low APGAR score was noted in $41.1 \%$ of MSAF cases. At 5 minutes, the low APGAR score cases reduced to $25 \%$ but was much higher than controls with strong statistical significance. Low APGAR score at 1 and 5 minutes is noted in MSAF and is more often noted in cases with thick meconium. Low APGAR score was noted in $44.4 \%$ and $55.5 \%$ at 1 and 5 minutes respectively in cases with thick meconium compared to cases with thin meconium with low APGAR score in $14 \%$ and $86 \%$ at 1 and 5 minutes respectively which is statistically significant ( $\mathrm{p}$ value of 0.043 ). On comparing the thin and thick subgroups, it was the thick subgroup with high incidence of NICU admission. Nearly half of the cases with thick meconium needed NICU admission and only $12 \%$ of cases with thin meconium needed NICU admission. Perinatal complications were seen in 13 cases out of which 3 developed MAS, 8 developed HIE, 2 babies developed sepsis.

\section{DISCUSSION}

This was a short research project which was carried out in duration of 6 months. Out of 500 patients selected for the present study which had inclusion criteria, $13.6 \%$ were meconium stained out of which $50(73.5 \%)$ cases had thin meconium and $18(26.4 \%)$ cases had thick meconium. So, the incidence of meconium-stained liquor in our study is $13.6 \%$ This is similar to study conducted byAddisu et al on prevalence of meconium-stained amniotic fluid and its associated factors among women who gave birth at term. As Per their study the prevalence of meconium-stained amniotic fluid was $17.8 \%$ with $(95 \%$ $\mathrm{CI}=14.3-21.2) .^{7}$ Out of 68 patients with meconium, 50 $(73.5 \%)$ cases had thin meconium and $18(26.4 \%)$ cases had thick meconium. In a study, on fetal outcome in deliveries with meconium-stained liquor by Vaghela et al; 38\% patients had thin meconium, 34\% had moderate, $28 \%$ had thick meconium. ${ }^{8}$ They had divided the meconium-stained liquor into 3 categories. Here, if we merge moderate and thin meconium then our result is almost same.

In this study, on comparing the subgroups of thick and thin meconium, it was the thick group where operative intervention was more commonly needed. Also, fetal CTG abnormalities were more common in MSAF group and were noted in $38.2 \%$ of cases which is significantly increased compared to control group. this is comparable to studies, by Divia et al and Adda et al which also highlighted that $86 \%$ of the thick stained amniotic fluid group (grades two and three) undergoes operative delivery which indicates the risk of fetal heart rate abnormality with meconium staining and cesarean section being used as a rescue for infants who are about to develop MAS. This is in line with other studies showing a higher risk of complications with thick meconium staining. ${ }^{9,10}$ In this study, at 1 minute the low APGAR score was noted in $41.1 \%$ of MSAF cases. At 5 minutes, the low APGAR score cases reduced to $25 \%$ but was much higher than controls with strong statistical significance. Low Apgar score at 1 and 5 minutes is noted in MSAF and is more often noted in cases with thick meconium. Low APGAR score was noted in $44.4 \%$ and $55.5 \%$ at 1 and 5 minutes respectively in cases with thick meconium compared to cases with thin meconium with low APGAR score in $14 \%$ and $86 \%$ at 1 and 5 minutes respectively which is statistically significant ( $p$ value of 0.043). This is more in percentage as compared to studies by Patil et al study, which reported that $19 \%$ of babies with MSAF had poor APGAR scores. ${ }^{11}$

On comparing the thin and thick subgroups, it was the thick subgroup with high incidence of NICU admission. Nearly half of the cases with thick meconium needed NICU admission and only $12 \%$ of cases with thin meconium needed NICU admission. Among these, Perinatal complications were seen in 13 cases out of which 3 developed MAS, 8 developed HIE, 2 babies developed sepsis. However, there was no perinatal 
mortality. However, other studies have shown, mortality rate of $3 \%$ in cases with thick meconium and $2 \%$ in cases of thin meconium. As per a study by Gupta et al found
$4.9 \%$ mortality in meconium-stained amniotic fluid. ${ }^{12}$ The difference is mainly due to urgent cesarean section and efficient NICU facility in our hospital.

Table 6: Meconium first observed and mode of delivery.

\begin{tabular}{|c|c|c|c|c|c|}
\hline \multirow{2}{*}{ Meconium detection } & \multirow{2}{*}{ Type of meconium } & \multirow{2}{*}{$\mathbf{N}$} & \multicolumn{2}{|l|}{ Mode of delivery } & \multirow[b]{2}{*}{ LSCS } \\
\hline & & & Vaginal delivery & Asst. vaginal & \\
\hline \multirow{2}{*}{ Latent phase } & Thin & 18 & 12 & 2 & 4 \\
\hline & Thick & 6 & 2 & 1 & 3 \\
\hline \multirow{2}{*}{ Active phase } & Thin & 22 & 13 & 3 & 6 \\
\hline & Thick & 7 & 3 & 2 & 2 \\
\hline \multirow{2}{*}{ Second stage } & Thin & 10 & 6 & 1 & 3 \\
\hline & Thin & 5 & 2 & 2 & 1 \\
\hline
\end{tabular}

Table 7: APGAR score at 1 and 5 minutes.

\begin{tabular}{|c|c|c|c|c|}
\hline \multirow[b]{2}{*}{ Parameters } & \multicolumn{2}{|c|}{ Status N (\%) } & \multirow[b]{2}{*}{ Total $(n=500)$} & \multirow[b]{2}{*}{$P$ value } \\
\hline & $\begin{array}{l}\text { Cases } \\
(\mathrm{N}=68)\end{array}$ & $\begin{array}{l}\text { Control } \\
(\mathrm{N}=432)\end{array}$ & & \\
\hline \multicolumn{5}{|c|}{ APGAR score at 1 minute } \\
\hline$<5$ & $28(41.1)$ & $32(7.4)$ & $60(12)$ & \multirow[b]{2}{*}{0.0001} \\
\hline$>5$ & $40(58.8)$ & $400(92.5)$ & $440(80)$ & \\
\hline \multicolumn{5}{|c|}{ APGAR score at 5 minutes } \\
\hline$<7$ & $17(25.0)$ & $18(5.08)$ & $37(7.4)$ & \multirow{2}{*}{0.0001} \\
\hline$>7$ & $51(75.0)$ & $414(95.8)$ & $465(93.0)$ & \\
\hline
\end{tabular}

Table 8: APGAR score at 1 and 5 minutes in MSAF.

\begin{tabular}{|c|c|c|c|c|}
\hline \multirow[b]{2}{*}{ Parameters } & \multicolumn{2}{|c|}{ Cases $\mathbf{N}(\%)$} & \multirow[b]{2}{*}{ Total $(n=68)$} & \multirow[b]{2}{*}{ P value } \\
\hline & $\begin{array}{l}\text { Thin } \\
(\mathbf{N}=50)\end{array}$ & $\begin{array}{l}\text { Thick } \\
(\mathrm{N}=18)\end{array}$ & & \\
\hline \multicolumn{5}{|c|}{ APGAR score at 1 minute } \\
\hline$<5$ & $23(46)$ & $05(27.7)$ & $28(41.1)$ & \multirow[b]{2}{*}{0.124} \\
\hline$>5$ & $27(54)$ & $13(72.2)$ & $40(58.8)$ & \\
\hline \multicolumn{5}{|c|}{ APGAR score at 5 minutes } \\
\hline$<7$ & $07(14.0)$ & $08(44.4)$ & $15(22.05)$ & \multirow{2}{*}{0.0166} \\
\hline$>7$ & $43(86.0)$ & $10(55.5)$ & $53(77.9)$ & \\
\hline
\end{tabular}

Table 9: NICU admissions in cases.

\begin{tabular}{|c|c|c|c|c|}
\hline \multirow[b]{2}{*}{ NICU admissions } & \multicolumn{2}{|c|}{ Cases N (\%) } & \multirow[b]{2}{*}{ Total $(n=68)$} & \multirow[b]{2}{*}{ P value } \\
\hline & $\begin{array}{l}\text { Thin } \\
(\mathrm{N}=50)\end{array}$ & $\begin{array}{l}\text { Thick } \\
(\mathrm{N}=18)\end{array}$ & & \\
\hline Needed & $06(12)$ & $06(33.3)$ & $18(17.6)$ & \\
\hline Not needed & $44(88)$ & $12(66.6)$ & $56(82.3)$ & \\
\hline
\end{tabular}

\section{CONCLUSION}

Thus, this study concluded that thick MSL is associated with abnormal CTG changes, higher incidence of operative deliveries like LSCS, low APGAR score and more NICU admissions due to meconium aspiration syndrome (MAS), hypoxic ischaemic encephalopathy (HIE), and sepsis as compared to thin MSL. Thick MSL denotes acute stress in the fetus, thus it is associated with more perinatal morbidity and mortality as compared to thin MSL which denotes past fetal stress.

Funding: No funding sources

Conflict of interest: None declared

Ethical approval: The study was approved by the Institutional Ethics Committee 


\section{REFERENCES}

1. Mundhra R, Agarwal M. Fetal outcome in meconium stained deliveries. J Clin Diagn Res. 2013;7(12):2874.

2. Wong $\mathrm{S}$, Chow $\mathrm{K}$, Ho L. The relative risk of fetal distress' in pregnancy associated with meconiumstained liquor at different gestation. J Obstet Gynaecol. 2002;22(6):594-9.

3. Monen L, Hasaart T, Kuppens S. The etiology of meconium-stained amniotic fluid: pathologic hypoxia or physiologic foetal ripening?. Early Human Develop J. 2014;90(7):325-8.

4. Lee J, Romero R, Lee KA, Kim EN, Korzeniewski SJ, Chaemsaithong $\mathrm{P}$, et al. Meconium aspiration syndrome: a role for fetal systemic inflammation. Am J Obstet Gynecol. 2016;214(3):366. e1-9.

5. Singh G, Singh O, Thapar K. Neonatal outcome in meconium stained amniotic fluid: a hospital based study. Int J Contemp Pediatr2017;4:356-60.

6. Qadir S, Jan S, Chachoo JA, Parveen S. Perinatal and neonatal outcome in meconium stained amniotic fluid. Int J Reprod Contracept Obstet Gynecol. 2016;5: 1400-5.

7. Addisu D, Asres A, Gedefaw G, et al. Prevalence of meconium stained amniotic fluid and its associated factors among women who gave birth at term. BMC Pregnancy Childbirth. 2018;18:429.
8. Vaghela HP, Deliwala K, Shah P. Fetal outcome in deliveries with meconium stained liquor. IJRCOG. 2014;45:52.

9. Divia A. Study on risk factors and perinatal outcome in meconium-stained liquor in IOG. Madras Med Coll J. 2018:41:54-9.

10. Adda AB. Factors influencing meconium stained amniotic fluid (msaf) delivery outcomes at ridge hospital, Accra. Univ Ghana J. 2017;45:52-9.

11. Patil K, Swamy M, Samatha K. A one year crosssectional study of management practices of meconium-stained amniotic fluid and perinatal outcome. Obstet Gynecol India. 2006;56:128-30.

12. Gupta V, Bhatia BD, Mishra OP. Meconium stained amniotic fluid: Antenatal intrapartum and neonatal attributes. Indian Paediatr. 1996;33:293-7.

Cite this article as: Shukla JV, Patel AD,

Chandrayan P. Perinatal and maternal outcome in meconium stained amnioticfluid (thin and thick) at dhiraj general hospital, a rural tertiary health centre. Int J Reprod Contracept Obstet Gynecol 2022;11:192-6. 